\title{
Nanomaterials for Advanced Electrode of Low Temperature Solid Oxide Fuel Cells (SOFCs)
}

\author{
Tatsumi Ishihara ${ }^{\dagger}$ \\ International Institute for Carbon Neutral Energy Research (WPI-I'CNER), Kyushu University, Fukuoka 819-0395, Japan \\ (Received September 2, Accepted September 12, 2016)
}

\begin{abstract}
The application of nanomaterials for electrodes of intermediate temperature solid oxide fuel cells (SOFC) is introduced. In conventional SOFCs, the operating temperature is higher than $1073 \mathrm{~K}$, and so application of nanomaterials is not suitable because of the high degradation rate that results from sintering, aggregation, or reactions. However, by allowing a decrease of the operating temperature, nanomaterials are attracting much interest. In this review, nanocomposite films with columnar morphology, called double columnar or vertically aligned nanocomposites and prepared by pulsed laser ablation method, are introduced. For anodes, metal nano particles prepared by exsolution from perovskite lattice are also applied. By using dissolution and exsolution into and from the perovskite matrix, performed by changing $\mathrm{P}_{\mathrm{O} 2}$ in the gas phase at each interval, recovery of the power density can be achieved by keeping the metal particle size small. Therefore, it is expected that the application of nanomaterials will become more popular in future SOFC development.
\end{abstract}

Key words : Fuel Cells, Electrodes, Nanocomposites, Perovskites

\section{Introduction}

F uel cells directly convert fuel energy to electric power with significantly high efficiency than that of current power generator..$^{1-5)}$ Among the different types of fuel cells, the polymer-based proton exchange membrane fuel cells (PEMFCs) have been the most extensively studied because of their low operating temperature (around 353K), which makes them more amenable to portable and transportation (primarily automobile) applications, for which rapid startup from ambient temperature is desired. However, the fuel for PEMFCs is limited to hydrogen of high purity (and extremely low CO content). Therefore, considering the energy loss involved in $\mathrm{H}_{2}$ production, the overall efficiency of PEMFCs from fuel to electricity is at best only $<45 \%$.

In contrast, solid oxide fuel cells (SOFCs) use an oxide-ion conducting electrolyte instead of a proton conducting one. They transport oxygen from the cathode (air side) to oxidize fuel at the anode (fuel side), thus providing the ability to directly use a variety of hydrocarbon fuels with high fuel to electricity conversion efficiency (> 55\% lower heating value $[\mathrm{LHV}])^{2}{ }^{2}$ Moreover, in combined heat and power (CHP) applications in which the waste heat is utilized, the efficiency of SOFCs can exceed $85 \%,{ }^{6}$ ) which level is unmatched by any other energy conversion technology. Therefore, SOFCs are now attracting much interest for use in power

${ }^{\dagger}$ Corresponding author : Tatsumi Ishihara

E-mail : ishihara@cstf.kyushu-u.ac.jp

Tel : +81-92-802-2868 Fax : +81-92-802-2871 generators.

A typical SOFC consists of an electrolyte sandwiched between an anode and a cathode, with individual cells electrically connected in series by an interconnect to create an SOFC "stack". ${ }^{1-5)}$ For the last three decades, $\mathrm{Y}_{2} \mathrm{O}_{3}$ stabilized $\mathrm{ZrO}_{2}$ (YSZ) has been the SOFC electrolyte of choice because of its reasonably high conductivity, low cost, and good mechanical strength. ${ }^{1-3)}$ Due to the limited conductivity of YSZ, early SOFCs operated at the high temperature like $1273 \mathrm{~K}$. These excessively high temperatures result in high cell costs, long start-up and shut down cycles, and unacceptable performance degradation rates due to reactions between component materials and electrode sintering. Therefore, at present, to increase the long term stability, the important issue for SOFC development is to decrease the operating temperature. There are several reasons considered for power density degradation in SOFCs; ${ }^{6}$ 1) chemical impurities, 2) reactions between components, 3) sintering or aggregation, 4) delamination, etc. Among them, degradation of electrode activity by chemical impurities, in particular, degradation of the cathode by $\mathrm{S}$ or $\mathrm{Cr}$, is significant.

On the other hand, recently, from an energy storage point of view, there has also been strong interest in the reversible operation of SOFCs, the so-called "Solid Oxide Electrolysis Cells (SOECs)". Because renewable energy like that from wind mills or solar power generators is increasing, it is considered that excess electric power, beyond that demanded, will be generated, because renewable electric power fluctuates and is diluted. In order to store and average such excessively generated electric power, electrolysis of water is now attracting much interest. There are three types of electroly- 
sis cell: alkaline, polymer, and high temperature cells. For such cells, the efficiency of the conversion process of electricity to hydrogen is important. The conversion efficiency decreases in the following order, high temperature (ca. $90 \%$ ) > polymer (ca. 80\%) > alkaline (ca. 70\%). In high temperature electrolysis, the Gibbs free energy required for electrolysis decreases with increasing temperature due to the use of heat energy (T $\Delta \mathrm{S})$. Therefore, extremely high efficiency is achieved in high temperature electrolysis. However, there are still many issues that exist for SOECs; in particular, the degradation of the cells is more significant than it is for SOFCs. At present, materials used for SOECs are similar to those used for SOFCs; however, compared with SOFCs, SOECs will require more robust tolerance against oxidation and tighter gas sealing. ${ }^{7,8)}$

For both types of cells, the preparation method is based on the conventional processes of ceramic production, i.e., slip casting, screen printing, tape casting, etc. The materials used for electrodes are generally doped perovskite and $\mathrm{Ni}$ oxide cermet for the cathode and the anode, respectively. Because of the high operating temperature, nano size control of the electrode catalyst has not been studied up to now; however, because of the possibility of low temperature operation, nano size controlled materials are now attracting much interest for their ability to increase the power density of SOFCs. In this review, application of nano size control of an electrode catalyst is introduced.

\section{Application of Nano Size Controlled Oxide Film for Cathode}

Oxygen electrodes play highly important roles in the efficiency and superior activity of SOECs; stability of these electrode is also strongly required. The principal requirement for the cathodes of SOFCs is to electrochemically reduce oxygen molecules into oxide ion; there are several requirements for oxides applied as cathodes of SOFCs, i.e., catalytic activity, thermodynamic stability, and compatibility in terms of mechanical and chemical properties. Perovskite oxide is the most suitable material for satisfying these requirements for cathodes; $\mathrm{LaFeO}_{3}, \mathrm{LaCoO}_{3}$, or LaM$\mathrm{nO}_{3}$ doped with $\mathrm{Sr}$ or $\mathrm{Ca}$ have been widely used. Oxygen reduction proceeds on the electrode surface, in particular at the electrode/electrolyte/gas phase interface, so called three phase boundary (TPB), as shown in Fig. 1. The electrode material catalyzes the oxygen molecules, which are dissociated into atoms, charged, and incorporated into the electrolyte. Therefore, up to now, fine perovskite powders with mixed conductivity have mainly been studied. However, in conventional cathode materials, the reaction area is limited at the three phase boundary between the cathode, electrolyte, and gas phase, although the two phase boundary could also be used in the case of a mixed conducting oxide for a cathode. Expansion of the reaction area into three dimension has been reported by using a columnar structure film electrode, as schematically shown in Fig. 2.

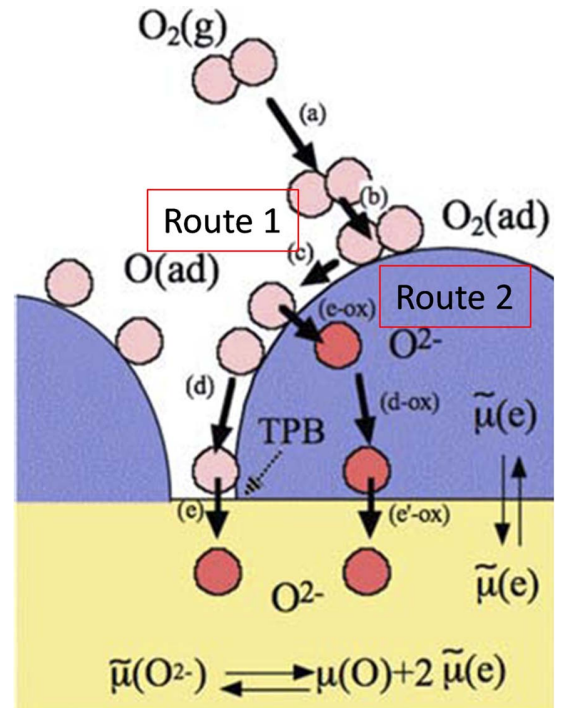

Fig. 1. Schematic image of cathodic reaction.

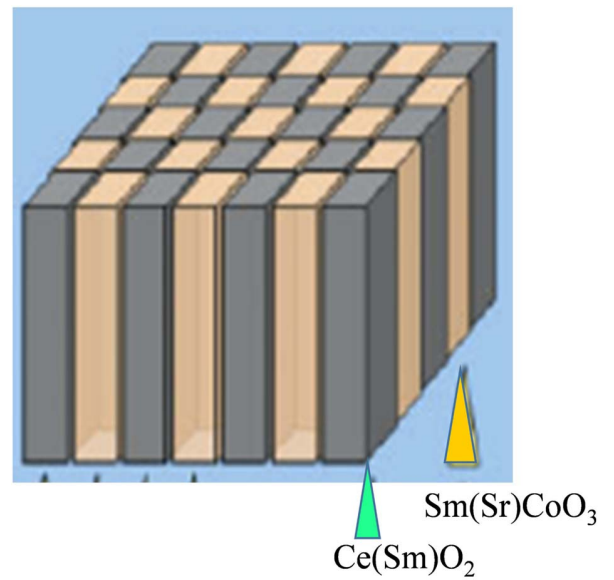

Fig. 2. Schematic image of double columnar structure electrode.

Wang et al. used a pulsed laser deposition (PLD) to fabricate a vertically aligned nanocomposite (VAN) structure consisting of $\mathrm{La}_{0.5} \mathrm{Sr}_{0.5} \mathrm{CoO}_{3}$ (LSC113) and Gd-doped ceria (GDC) on a GDC electrolyte, as shown in Fig. 3. ${ }^{9)}$ They observed that the VAN layer effectively improved the reaction kinetics by increasing the effective area of the threephase boundary (TPB) in the cathode. Furthermore, they observed a significant improvement in the power-generating property of the SOFCs with decreasing of the polarization overpotential (Fig. 4). However, they found that the VAN layer had a dense morphology and, as a result, it was difficult to explain how the TPB in the cathode had increased in size. Although they demonstrated that the area-specific resistance (ASR) decreased with increasing interface area density between LSC113 and GDC, they were not able to determine a mechanism to explain the increased ORR kinetics.

The same group also reported the expansion of the compo- 
sition of the VAN layer, i.e. to $\mathrm{PrBaCo}_{2} \mathrm{O}_{5} / \mathrm{Gd}_{0.1} \mathrm{Ce}_{0.9} \mathrm{O}_{2}{ }^{10)}$ and $\mathrm{La}_{0.8} \mathrm{Sr}_{0.2} \mathrm{MnO}_{3} / \mathrm{YSZ}^{11)}$ Vertically aligned nano-composites with similar morphology were prepared by PLD and in a similar manner; all combinations with VAN structures are effective at increasing the power density of SOFCs at low temperature. Fig. 5 shows the effects of the presence of a VAN layer between the cathode and the YSZ electrolyte.

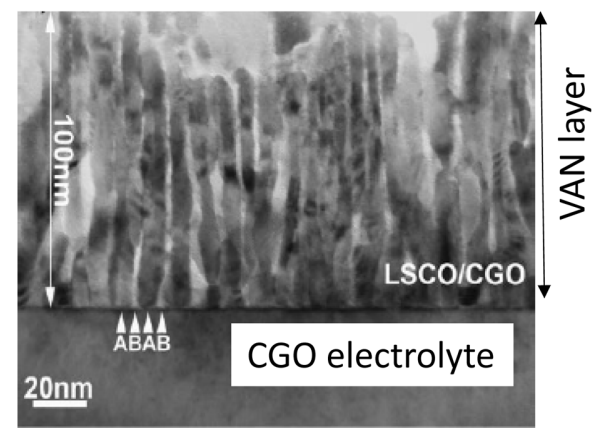

$$
\begin{aligned}
& \text { A:LSCO: } \mathrm{La}_{0.5} \mathrm{Sr}_{0.5} \mathrm{CoO}_{3} \\
& \text { B:CGO: } \mathrm{Ce}_{0.9} \mathrm{Ga}_{0.1} \mathrm{O}_{2}
\end{aligned}
$$

Fig. 3. TEM image of LSC113/GDC vertically aligned nanocomposite (VAN) (modified figure in Ref. 9).
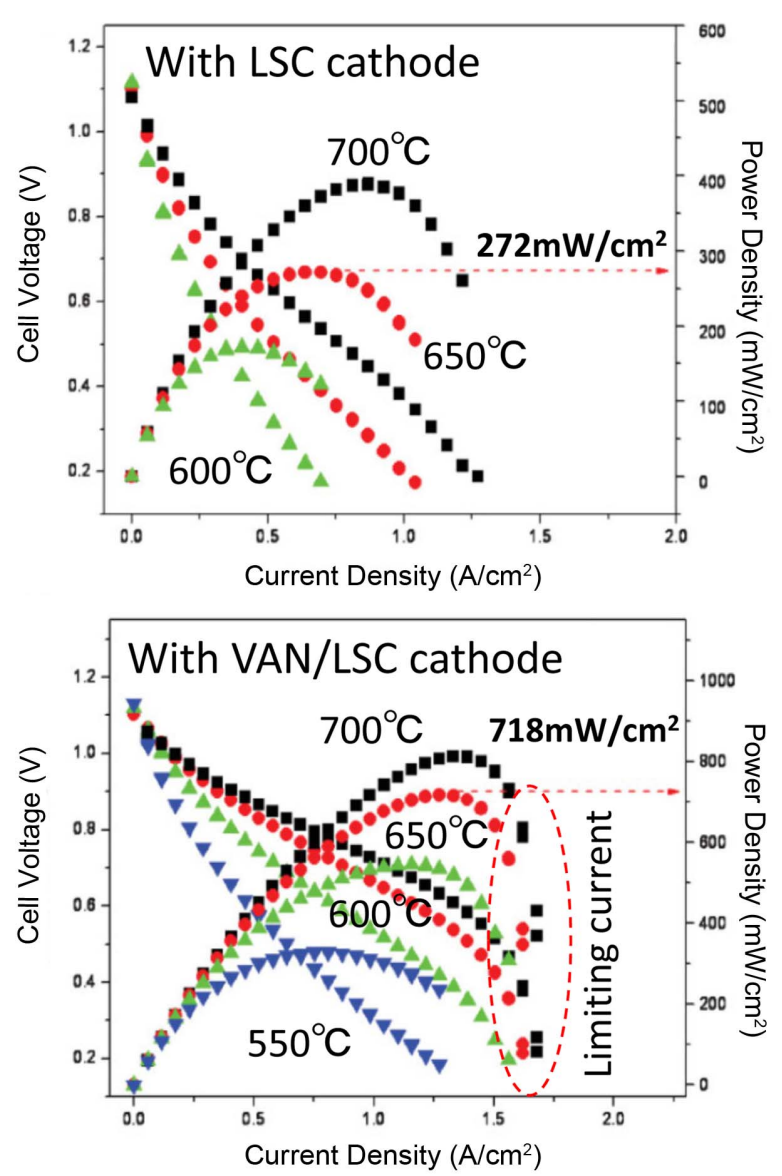

Fig. 4. Effects of LSC113/GDC VAN layer on power generation property (modified figure in Ref.9): (a)Without VAN layer (b) with VAN layer.
Obviously, a much higher power density was achieved by insertion of an LSM/YSZ VAN layer; maximum power densities of $0.22,0.32,0.43$, and $0.55 \mathrm{~W} \mathrm{~cm}^{-2}$ were achieved at 923, 973, 1023, and $1073 \mathrm{~K}$, respectively. Compared to the performance of a cell without an interlayer, the cells with interlayers had 2 times higher overall maximum power density, demonstrating that the VAN interlayer significantly enhances the oxygen reduction activity.

Our group also studied a similar approach to increasing the cathodic activity. ${ }^{12)}$ In our study, nano size columnar Sm doped $\mathrm{CeO}_{2}$ and $\mathrm{Sm}_{0.6} \mathrm{Sr}_{0.4} \mathrm{CoO}_{3}$ were also prepared by PLD method under higher oxygen partial pressure. A high resolution transmission electron microscopy (TEM) image of the prepared double columnar structure is shown in Fig. 6 (a, b); obviously, columnar structures consisting of two different compositions were successfully deposited on the electrolyte. It can be seen that the interface between the two oxides provides good contact and, at the grain boundary, an Sr gradient is achieved.

Figure 7 shows the power generation property of SOFC single cells fabricated using LSGM thin film electrolyte with and without a double columnar air electrode. In these cells, an Ni-Fe metallic anode substrate, $\mathrm{Sm}$ doped $\mathrm{CeO}_{2}$ buffer
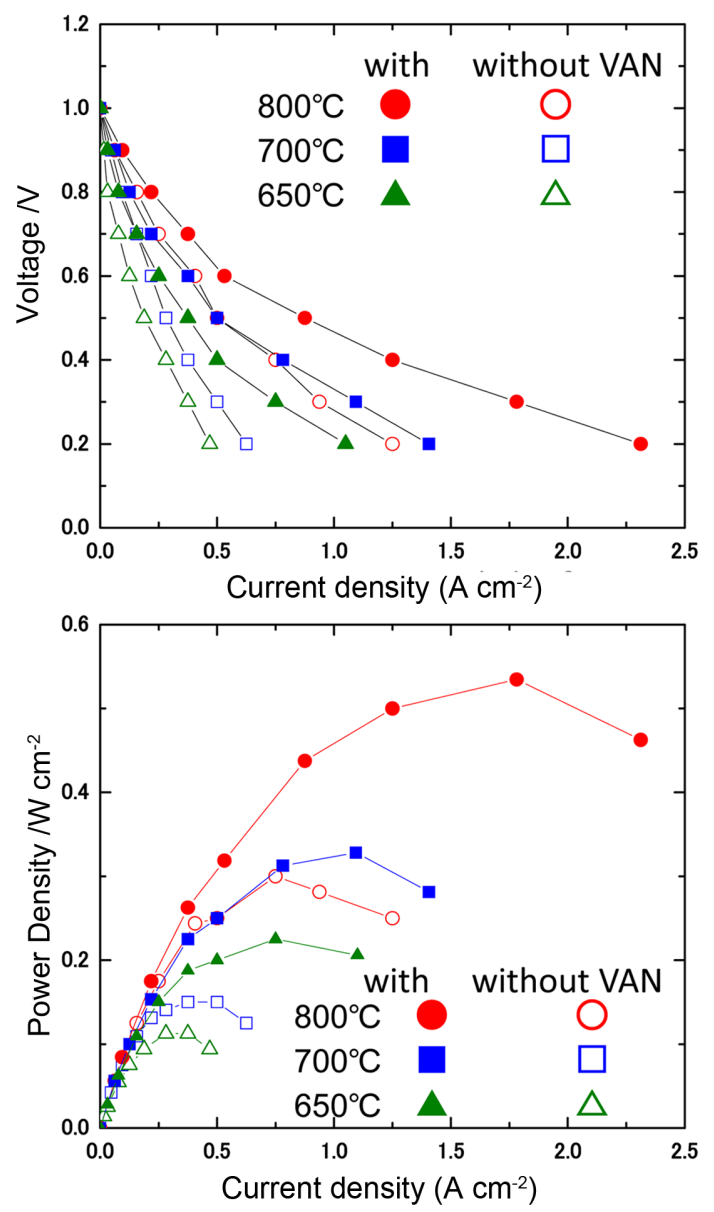

Fig. 5. Effects of LSM/YSZ VAN layer on power density of the cell using YSZ (Data coted from figure in Ref.11). 
(a)

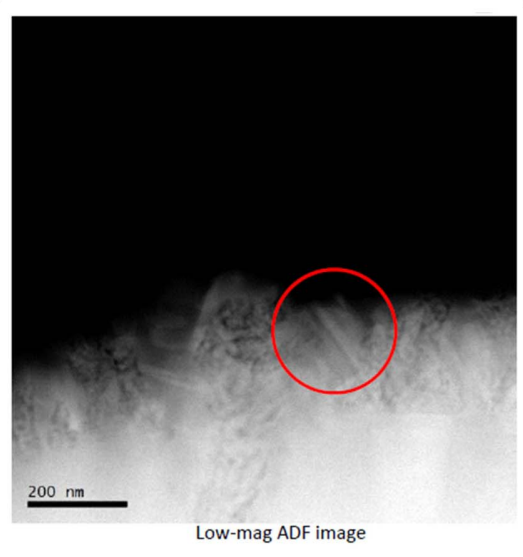

D1 $\Rightarrow$ SSC perovskite $[101]$ D2 $\Rightarrow$ SDC CaF 2 -type $[101]$ (b)

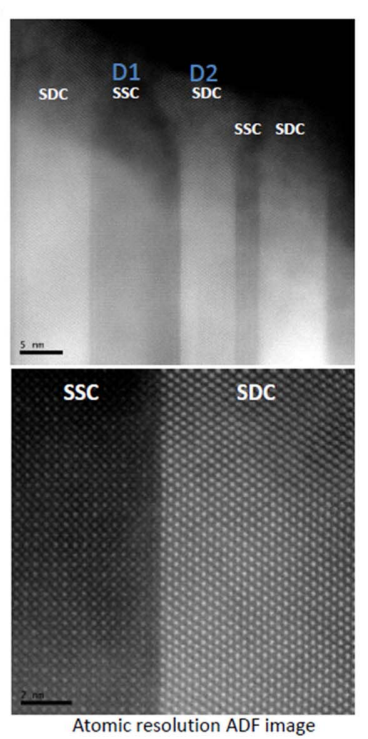

Fig. 6. (a) TEM and (b) high resolution images of double columnar structure between SSC/SDC.
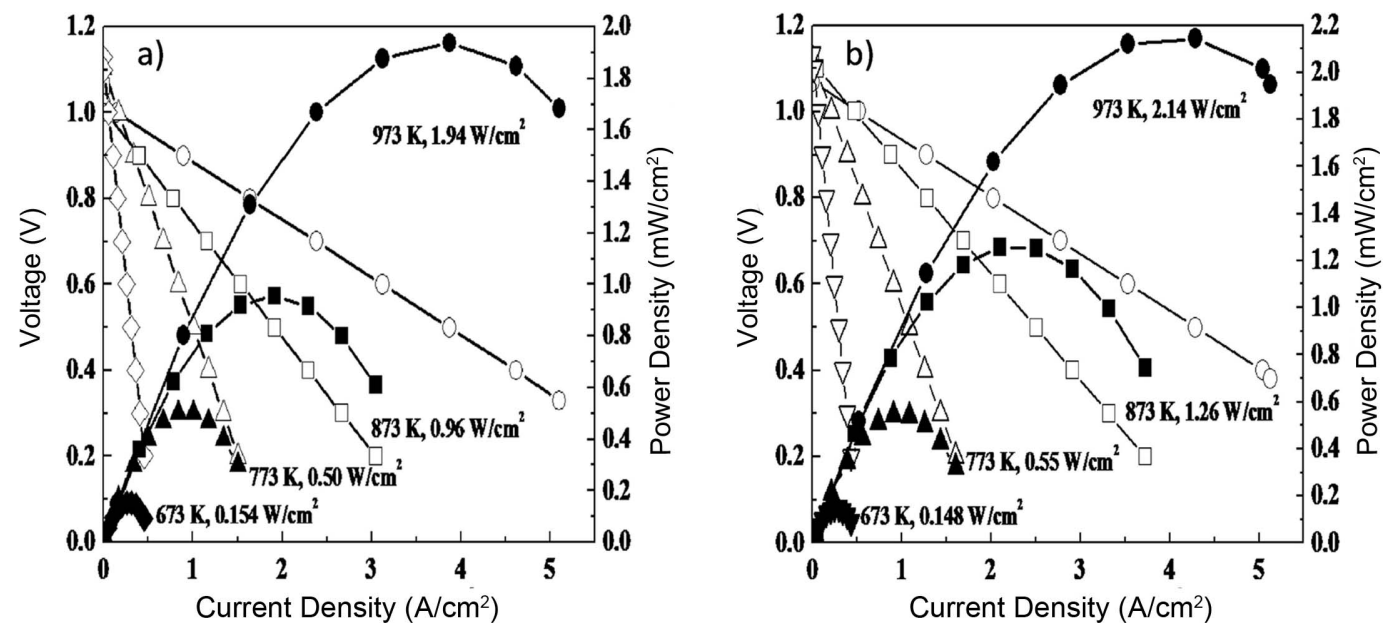

Fig. 7. Power generation property of the SOFC single cell (a) with and (b) without double columnar air electrode.

layer, and $\mathrm{La}_{0.9} \mathrm{Sr}_{0.1} \mathrm{Ga}_{0.8} \mathrm{Mg}_{0.2} \mathrm{O}_{3}$ oxide electrolyte $(5 \mathrm{~mm}$ thickness) were used. Although the double columnar layer is dense, the observed open circuit potential is close to the theoretical value $(1.10 \mathrm{~V})$ suggesting reasonable activity for oxygen dissociation. Because of the thin LSGM electrolyte film, a high power density of approximately $2 \mathrm{~W} / \mathrm{cm}^{2}$ at 973 $\mathrm{K}$ can be achieved. Detailed analysis of the internal resistance of the cell suggests that the increased power density can be attributed to the decreased cathodic overpotential. Therefore, control of the nano structure of the cathode, which means an increase of the two phase boundary corresponding to route 2 in Fig. 1, is highly important for the surface activity of oxygen dissociation into the oxide ion.

The formation of an $\mathrm{SmCoO}_{3-\delta}$ nano-gradient could result in lattice distortions, which would facilitate oxygen ion transport and oxygen vacancy formation in the hetero structure. Therefore, SIMS analysis was performed to confirm

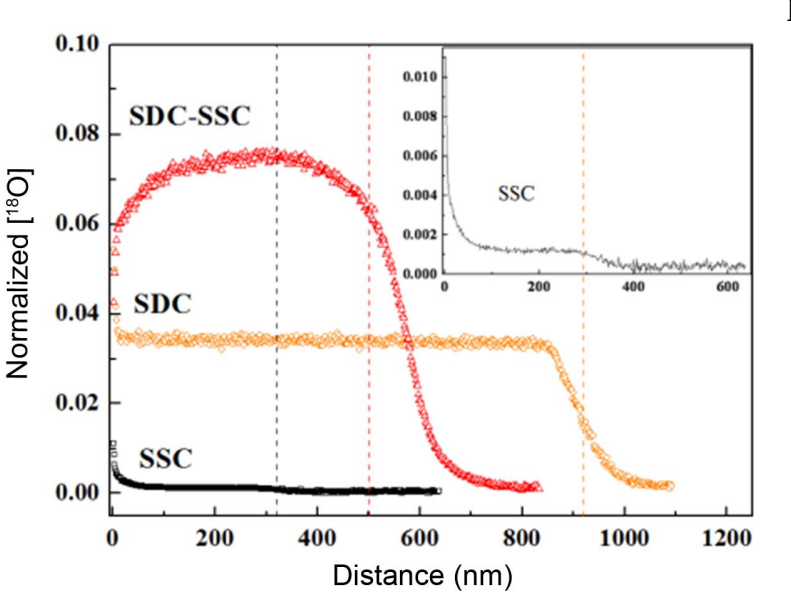

Fig. 8. ${ }^{18} \mathrm{O}_{2}$ depth profiles for SDC and SSC double columnar films. 
columnar layer. Oxygen isotope tracer exchange treatment was performed on the SDC film on $\mathrm{Al}_{2} \mathrm{O}_{3}$, on the SSC film, and on the SSC-SDC film on $\mathrm{MgO}$ at $573 \mathrm{~K}$. Fig. 8 shows the ${ }^{18} \mathrm{O}_{2}$ depth profiles for the films: the SDC and SSC films showed typical tracer profiles, but the SSC-SDC film on the $\mathrm{MgO}$ substrate gave an abnormal profile. The ${ }^{18} \mathrm{O}_{2}$ concentration for the double columnar layer was almost flat except near the surface of the film. Kubieck et al. also observed flat tracer profiles for $\mathrm{La}_{1-\mathrm{x}} \mathrm{Sr}_{\mathrm{x}} \mathrm{CoO}_{3-\delta}$ (LSC) on $\mathrm{SrTiO}_{3}$ (STO). ${ }^{13)}$ They determined that the flat profile was related to the high diffusivity of oxygen in the LSC/STO system. ${ }^{13)}$ Therefore, our results could be explained by high oxygen diffusivity through the double columnar layer, which may be the interface. The concentration of ${ }^{18} \mathrm{O}_{2}$ was lower near the surface of the SSC-SDC film than elsewhere, and this depressed surface ${ }^{18} \mathrm{O}_{2}$ concentration may be related to faster oxygen diffusion rather than to surface dissociation. This means that fast oxygen diffusion could lead to surface oxygen dissociation being the rate determining step. Surface oxygen may diffuse from but not be supplied quickly by the gas phase. Further investigation will be necessary to understand the abnormal ${ }^{18} \mathrm{O}_{2}$ profile. However, even when there was an insufficient oxygen concentration near the surface of the SSC-SDC, the double columnar layer gave a considerably higher ${ }^{18} \mathrm{O}_{2}$ concentration than those of the SDC or SSC films. These results indicate that adding a double columnar layer significantly increases the oxygen diffusivity in a sample. This increase in diffusivity may be related to lattice distortion, caused by the formation of the $\mathrm{SmCoO}_{3-8}$ nanogradient at the interface of the columns.

In the case of SOEC, the function of the air electrode is opposite to that of the cathode of an SOFC, i.e., it is the combination of oxide ions into oxygen molecules. Therefore, the air electrode is always under a high oxygen pressure of approximately $100 \mathrm{MPa}$, depending on the pumping current. Under such a high oxygen partial pressure, excess oxygen comes into the interstitial sites, resulting in expansion. Therefore, in case of the air electrode of the SOEC, delamination of the air electrode is a serious issue. This is more significantly true for $\mathrm{LaMnO}_{3}$ based oxide. In order to achieve long term stability, preventing the air electrode delamination caused by excess oxidation is also required. Since a double columnar electrode is highly stable and has good tolerance for changes in volume due to excess oxidation, it is expected that superior performance can also be achieved for the oxygen evolution reaction.

\section{Nano Structure Controlled Anode for SOFC}

In the previous section, investigations of nanomaterials for the cathodes of SOFCs were introduced. In this section, another approach to nanomaterials for use in SOFC anodes will be introduced, namely, nano particles deposited by exsolution from an oxide lattice. On the anode of an SOFC, fuel, typically, $\mathrm{H}_{2}$ or $\mathrm{CH}_{4}$, is catalytically oxidized with oxide ion permeated through the solid electrolyte. Therefore, in a manner similar to that of the cathode, it is considered that the active site of the anode is limited to the three phase boundary, the interface between the anode, fuel, and electrolyte. For the anode, Ni shows high activity and the most popular element used. However, because Ni has only the ability to conduct, the reaction area is also limited to the TPB between the anode, electrolyte, and gas phase. In order to expand the reaction site from two dimensions to three dimension, mixing of the oxide ion conductor, of which the most popular one is YSZ, with $\mathrm{Ni}$ is performed and as shown in Fig. 9; the reaction site can be expanded into the anode. This composite of $\mathrm{Ni}$ and an oxide ion conductor is called a "cermet" and is effective not only at expanding the reaction area but also at preventing $\mathrm{Ni}$ aggregation. Since Ni aggregates easily at high temperature, coarsening of the Ni particles is one of the main reasons for the decreasing anodic activity.

It has been reported recently that exsolution is a useful method for preparing nano metal particles; it has also been reported that the resulting oxide is highly active for the anodic reaction. Since a perovskite structure is a highly sta-

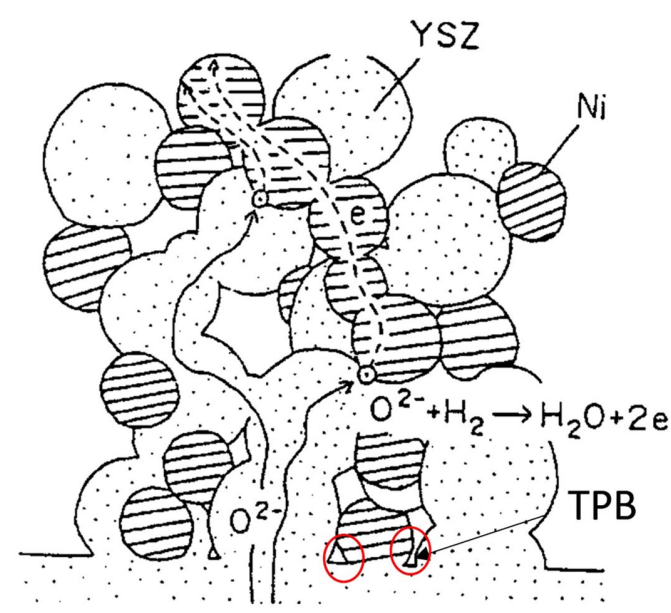

Fig. 9. Schematic image of anodic reaction on Ni-oxide ion conductor mixture anode.

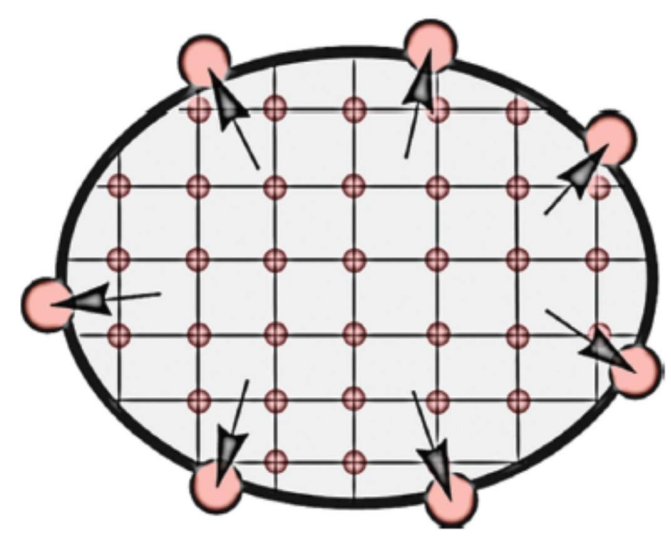

Fig. 10. Schematic image of exsolution of components from perovskite oxide. 
ble one, components in the $\mathrm{B}$ site can be exsoluted and deposited on the surface as nano particles via non-stoichiometry after reduction. Fig. 10 shows a schematic image of the exsolution of components from perovskite oxide with non-stoichiometric composition, which means an excess or deficient composition of the perovskite oxide $\left(\mathrm{ABO}_{3}\right)$.

Originally, exsolution of metal particles was reported for $\mathrm{Pd}$ from $\mathrm{LaFe}(\mathrm{Pd}) \mathrm{O}_{3}$ based perovskite for use as an automotive exhaust catalyst. Since coarsening of precious metals is the main reason for deactivation of three way catalysts, $\mathrm{Pd}$ nano particles are automatically regenerated by dissolution and exsolution of $\mathrm{Pd}$ into an $\mathrm{LaFeO}_{3}$ perovskite with oxidation and reduction treatment. Since nano size particles were regenerated by cyclic oxidation and reduction, this catalyst concept is called "intelligent catalyst". ${ }^{14)}$

Figure 11 provides a high resolution electron micrograph of the Ni particles exsoluted from $\mathrm{La}_{0.8} \mathrm{Ce}_{0.1} \mathrm{Ni}_{0.4} \mathrm{Ti}_{0.6} \mathrm{O}_{3}$ oxide and the mode of the deposited $\mathrm{Ni}^{15)} \mathrm{It}$ is interesting that the $\mathrm{Ni}$ particles, with diameters of a few $\mathrm{nm}$, are mainly deposited at the terrace surface and, obviously, the nano particles are deposited on the selected surface (110); these results are due to matching of the crystal plane and are strongly related with the nonstoichiometry of the host oxide. Usu- ally, metallic nano particles to be loaded can be deposited from the liquid phase and, as such, nano particles exist on the surface without any interaction with the oxide, as schematically shown in Fig. 12. However, as can be seen in Fig. 12(b), exsoluted $\mathrm{Ni}$ is an anchored structure because part of the metal particles are buried deep in the host oxide phase. Therefore, in spite of the large surface area, Ni nano particles prepared by exsolution method are stable against sintering or aggregation; this morphology is also tolerant against carbon deposition. ${ }^{16)}$ Sun et al. reported that the power density of SOFCs using $\mathrm{Ni}$ anodes exsoluted from $\mathrm{La}_{0.6} \mathrm{Sr}_{0.4} \mathrm{CrO}_{3}$ is high $\left(310 \mathrm{~mW} / \mathrm{cm}^{2}\right.$ at $1073 \mathrm{~K}$ for $\mathrm{H}_{2}$ fuel $)$ because of the high conductivity and small overpotential. ${ }^{17)}$

The authors' group also studied $\mathrm{Pd}$ exsoluted from $\mathrm{La}(\mathrm{Sr}) \mathrm{Fe}(\mathrm{Mn}) \mathrm{O}_{3}$ for direct hydrocarbon type fuel cells. ${ }^{18)}$ Since $\mathrm{Pd}$ is easily oxidized and reduced by setting the atmosphere at reducing and oxidizing, respectively, exsolution and dissolution from and into perovskite phase are observed. Fig. 13 shows a TEM image of the $\mathrm{La}_{0.6} \mathrm{Sr}_{0.4}$ $\mathrm{Fe}_{0.85} \mathrm{Pd}_{0.05} \mathrm{Mn}_{0.1} \mathrm{O}_{3}$ (LSFMP) after $1073 \mathrm{~K} \mathrm{H}_{2}$ treatment followed by air calcination. In order to confirm the redox reaction of Pd, X-ray photoelectron spectroscopy (XPS) analysis was performed on the LSFMP in the oxidation and reduc- (a)

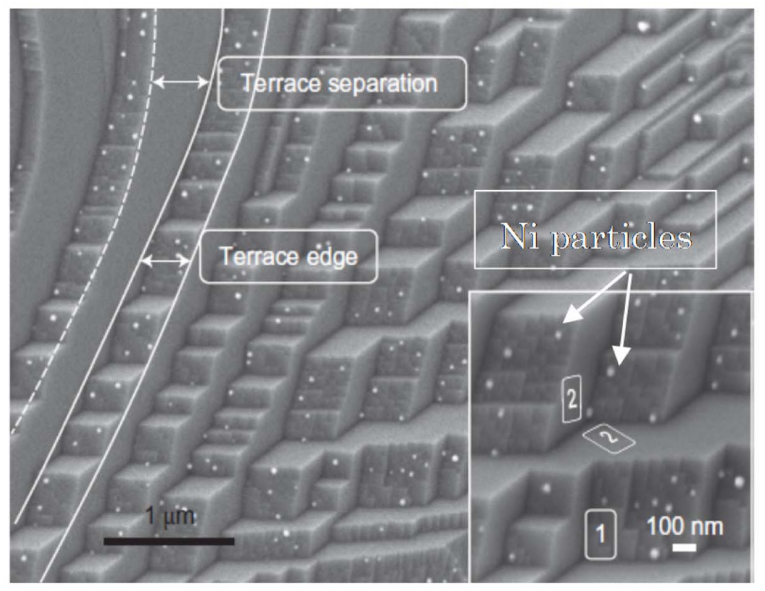

(b)

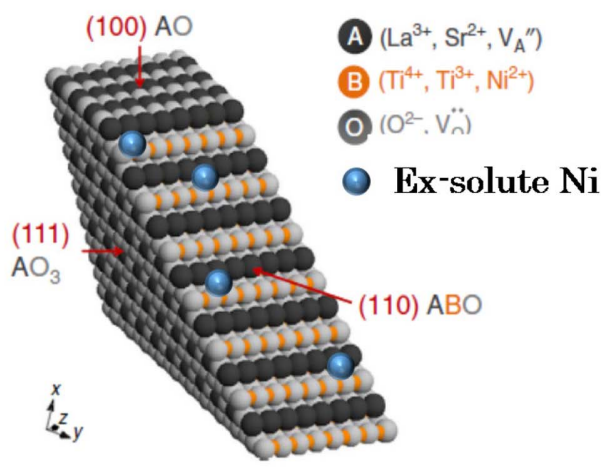

Fig. 11. (a) High resolution SEM image of $\mathrm{Ni}$ particles exsoluted from $\mathrm{La}_{0.8} \mathrm{Ce}_{0.1} \mathrm{Ni}_{0.4} \mathrm{Ti}_{0.6} \mathrm{O}_{3}$ oxide and (b) model of deposited $\mathrm{Ni}$ (modified figure in Ref.16).

(a)

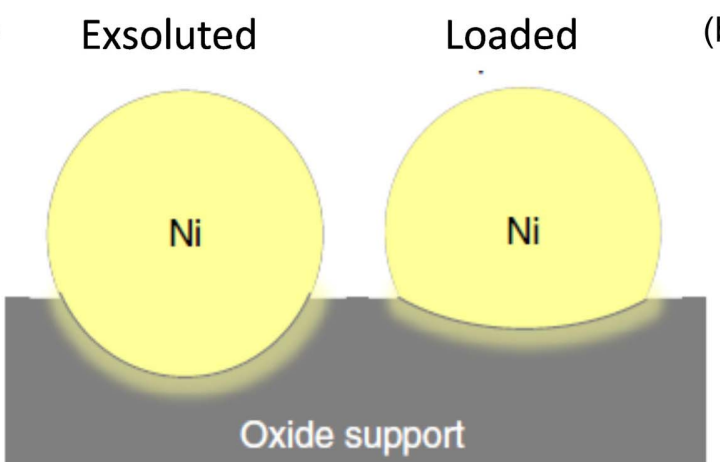

(b)

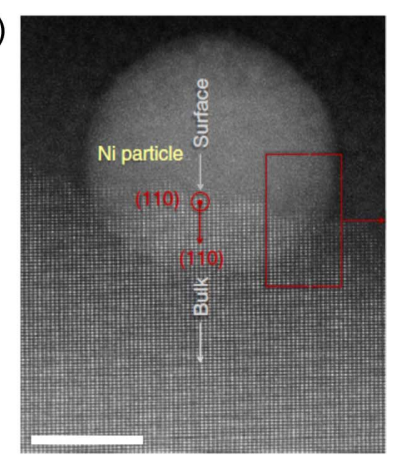

Fig. 12. (a) Schematic image of loaded and exsoluted nano particles; (b) TEM image of Ni exsoluted nano particles (modified figure in Ref.16). 

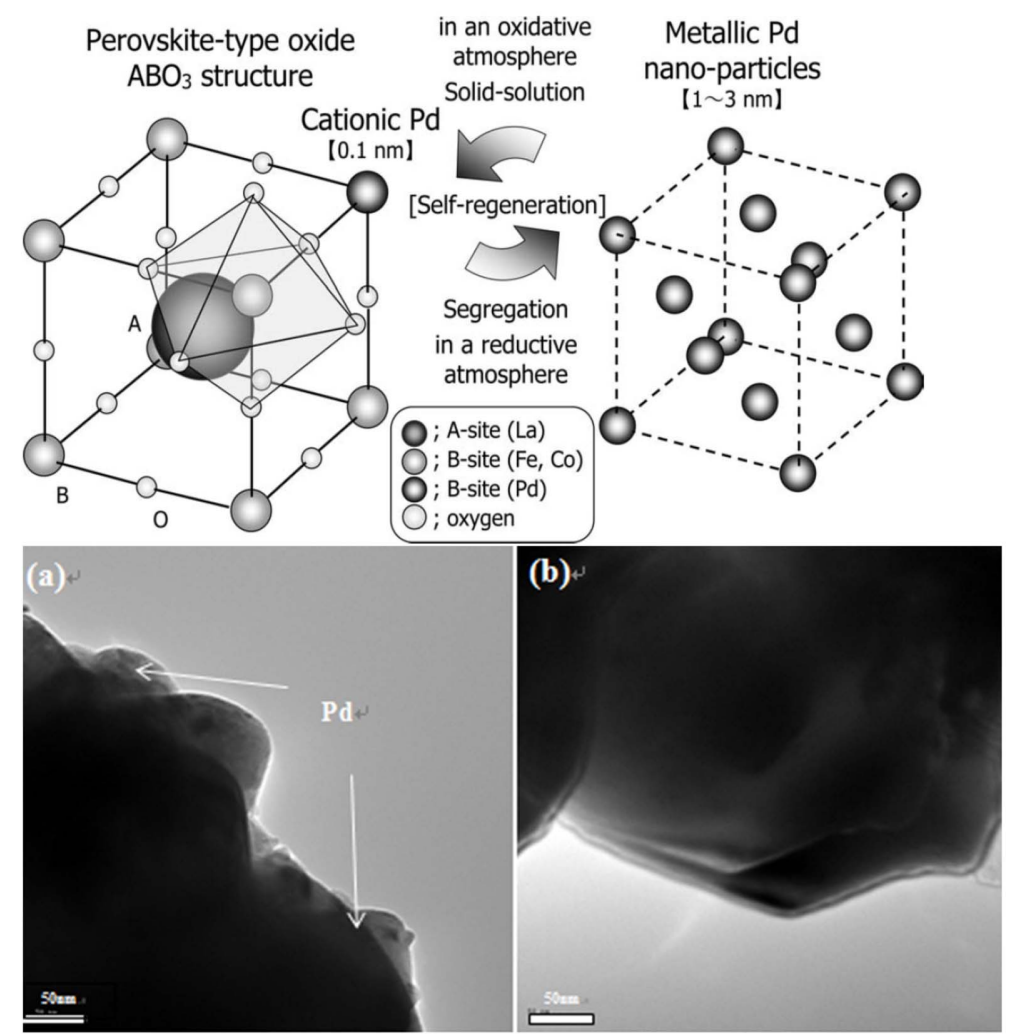

Fig. 13. TEM image of $\mathrm{La}_{0.6} \mathrm{Sr}_{0.4} \mathrm{Fe}_{0.85} \mathrm{Pd}_{0.05} \mathrm{Mn}_{0.1} \mathrm{O}_{3}$ (LSFMP) after $1073 \mathrm{~K} \mathrm{H}$ treatment followed by air calcination.

tion treatment. XPS measurements suggest that Pd might exist on the LSFMP surface as $\mathrm{Pd}^{0+}$, resulting from the reduction conditions of $\mathrm{H}_{2}$. On the other hand, the oxidation state of LSFMP in air at $1073 \mathrm{~K}$ showed almost the same binding energy as those of the $\mathrm{PdO}$ standards, so the oxidation state of $\mathrm{Pd}$ in LSFMP was considered to be $\mathrm{Pd}^{2+}$ in air at $1073 \mathrm{~K}$. These redox reactions of $\mathrm{Pd}$ are highly effective at maintaining a small particle size of $\mathrm{Pd}$ and a stable power density of the SOFCs.

Recovery of anode performance upon exposure to air was also studied. Fig. 14 (a) shows the long-term stability of the cell using the LSFMP anode with several redox cycles during operation, compared to the anodic property without the redox cycle, as shown in Fig. 14(a). When no redox treatment was performed, the terminal voltage gradually decreased, suggesting that the sintering of Pd particles and the degradation of the power density could be assigned to the increased anodic overpotential. In contrast, after applying several redox cycles, the terminal voltage was sustained for over 100 h. Fig. 14 (b) shows the details of the potential change during reoxidation treatment at $1073 \mathrm{~K}$ and with constant current density of $0.5 \mathrm{~A} \mathrm{~cm}^{-2}$. The initial maximum power density showed a fairly high performance after reduction, followed by continuous degradation until the cell stabilized at $0.56 \mathrm{~V}$ after $50 \mathrm{~h}$. This decrease in power density could be assigned to the enlarged IR loss and anodic overpotential. However, evidently, the cell performance was improved by re-oxidation treatment; the LSFMP anode was exposed to air at $1073 \mathrm{~K}$ for ca.10 h. The open circuit voltage (OCV) and the voltage measured at $0.5 \mathrm{~A} \mathrm{~cm}^{-2}$ immediately increased to 1.128 and $0.95 \mathrm{~V}$, slightly higher than the initial OCV and voltage values after the redox cycles. This degradation for long term and improved performance by reoxidation might be explained by the behavior of the dissolved $\mathrm{Pd}$ and by considering the process of exsolution into and from the perovskite lattice. In cases of longer wait times after a redox cycle, as shown in Fig. 14(a), the terminal voltage became much higher after $100 \mathrm{~h}$ operation. This is a typical advantage of intelligent catalysts. As a result, nano particles, in particular, Ni nano particles obtained by exsolution method, are highly interesting for use as stable and active anodes for SOFCs.

$\mathrm{Ni}$ based nano particles obtained by exsolution method from $\mathrm{SrTiO}_{3}$ based perovskite were also applied for SOEC cathodes. ${ }^{19)}$ B-site doped, A-site deficient perovskite titanates with the formula $\mathrm{La}_{0.4} \mathrm{Sr}_{0.4} \mathrm{Mn}\left(\right.$ or $\mathrm{Fe}$ ) $\mathrm{TiO}_{3}$ were employed as solid oxide electrolysis cell (SOEC) cathodes for hydrogen production via high temperature steam electrolysis at $1173 \mathrm{~K}$. The A-site deficiency provided an additional driving force for the exsolution of a proportion of the B-site dopants at the surface in the form of metallic nanoparticles under reducing SOEC cathode operating conditions. In the case of $\mathrm{La}_{0.4} \mathrm{Sr}_{0.4} \mathrm{Fe}_{0.06} \mathrm{Ti}_{0.94} \mathrm{O}_{2.97}, \mathrm{Fe}$ is for the first time exsolved from perovskite. After exsolution of the $\mathrm{B}$ site com- 

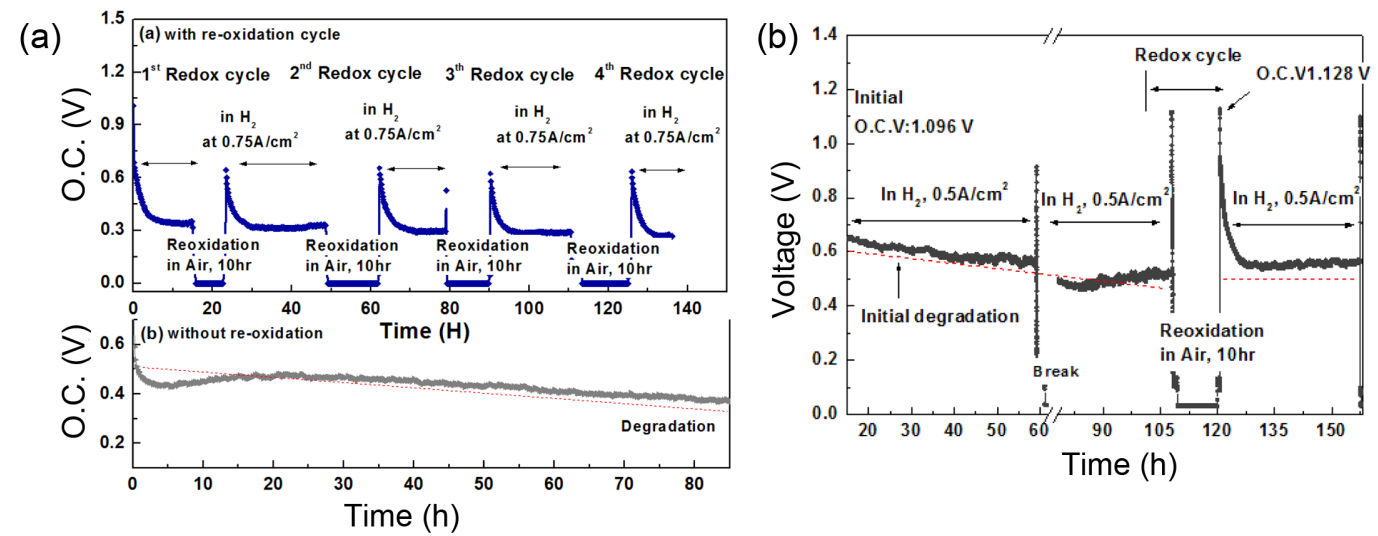

Fig. 14. (a) Long term stability of the cell using LSPFM anode at constant current density around $0.8 \mathrm{~A} \mathrm{~cm}{ }^{-2}$ with 4 times reoxidation cycle, (b) cell performance during redoc cycle using LSFMP anode at $1073 \mathrm{~K}$.

ponent, oxygen vacancies were introduced and it is suggested that the presence of electrocatalytically active Fe or Ni nanoparticles and higher $\mathrm{V}_{\mathrm{O}}$ “ concentrations dramatically lowered the activation barrier to steam electrolysis compared to the case of the conventional $\mathrm{Ni}$ cathode. The use of defect chemistry to drive the exsolution of less reducible dopant cations could conceivably be extended to produce new catalytically active perovskites with unique properties.

The exsolution method has mainly been studied for fuel electrodes, but has also been studied for air electrodes in which Ag nano particles are exsoluted. ${ }^{20)}$ As a result, metal nano particles deposited from a perovskite oxide are highly interesting; it is considered that improved electrode activity can not only be assigned to the formed nano particles but also to the nonstoichiometric perovskite, which contains a large number of oxygen vacancies.

\section{Summary}

The operating temperature of conventional SOFCs can be very high, with levels of $1173 \mathrm{~K}$; so, nanomaterials have not been applied extensively up to now. However, due to the development of promising fast oxide ion conductors such as LSGM, or thin film conventional electrolytes like YSZ, intermediate temperature operation has now been realized and the operating temperature of SOFCs has now decreased to around $873 \mathrm{~K}$. Therefore, nano size materials can be now used for SOFC components. In this review, a cathode interface with a double columnar structure, and also nano particles prepared by exsolution method, were introduced. By controlling the structure of the electrode or the interface at the nano level, much higher power density or stability can be achieved. As a result, it can be said that nanomaterials will lead to a future of new application areas for SOFCs for example, mobile applications.

\section{Acknowledgments}

Part of this study was financially supported by a Grant-in-
Aid for specially promoted research (no. 16H06293) from MEXT, Japan.

\section{REFERENCES}

1. N. Q. Minh, "Ceramic Fuel Cells," J. Am. Ceram. Soc., 76 563-88 (1993).

2. S. Singhal, K. Kendall, "High-Temperature Solid Oxide Fuel Cells: Fundamentals, Design and Applications; Elsevier, Oxford, 2003.

3. S. C. Singhal, "Advances in Solid Oxide Fuel Cell Technology," Solid State Ionics, 135 305-13 (2000).

4. T. Ishihara, Perovskite Oxide for Solid Oxide Fuel Cells (Fuel Cells and Hydrogen Energy); Springer, New York, 2009.

5. J. H. Hirschenhofer, D. B. Stauffer, R. R. Engleman, and M. G. Klett, Fuel Cell Handbook; 7th Editon, U. S. Department of Energy, Morgantown, 2004.

6. H. Yokokawa, "Towards Comprehensive Description of Stack Durability/ Reliability Behavior," Fuel Cells, 15 65268 (2015)

7. R. Knibbe, M. L. Traulsen, A. Hauch, S. D. Ebbesen, and M. Mogensen, "Solid Oxide Electrolysis Cells: Degradation at High Current Densities," J. Electrochem. Soc., 157 B1209-17 (2010).

8. M. Ni, M. K. H. Leung, and D. Y. C. Leung, "Technological Development of Hydrogen Production by Solid Oxide Electrolyzer Cell (SOEC)," Int. J. Hydrogen Energy, 33 2337-54 (2008).

9. J. S. Yoon, S. M. Cho, J. H. Kim, J. H. Lee, Z. Bi, A. Serquis, X. Zhang, A. Manthiram, and H. Wang, "Vertically Aligned Nanocomposite Thin Films as a Cathode/Electrolyte Interface Layer for Thin-Film Solid-Oxide Fuel Cells," Adv. Funct. Mater. 19 3868-73 (2009).

10. S. Cho, Y. N. Kim, J. H Lee, A. Manthiram, and H. Wang, Microstructure and Electrochemical Properties of PrBa$\mathrm{Co}_{2} \mathrm{O}_{5+1} / \mathrm{Ce}_{0.9} \mathrm{Gd}_{0.1} \mathrm{O}_{1.95}$ Vertically Aligned Nano-Composite Thin Film as Interlayer for Thin Film Solid Oxide Fuel Cells," Electrochim. Acta, 62 147-52 (2012)

11. Q. Su, D. Yoon, Z. Sisman, F. Khatkhatay, Q. Jia, A. Manthiram, and H. Wang, "Vertically Aligned Nanocomposite 
$\mathrm{La}_{0.8} \mathrm{Sr}_{0.2} \mathrm{MnO}_{3} / \mathrm{Zr}_{0.92} \mathrm{Y}_{0.08} \mathrm{O}_{1.96}$ Thin Films as Electrode/Electrolyte Interfacial Layer for Solid Oxide Reversible Fuel Cells," Int. J. Hydrogen Energy, 38 16320-27 (2013).

12. Y. W. Ju, J. Hyodo, A. Inoishi, S. Ida, T. Tohei, Y.-G. So, Y. Ikuhara, and T. Ishihara, "Double Columnar Structure with a Nanogradient Composite for Increased Oxygen Diffusivity and Reduction Activity," Adv. Energy Mater., 4 [17] 1400783/1-8 (2014)

13. M. Kubicek, Z. Cai, W. Ma, B. Yildiz, H. Hutter, and J. Fleig, "Tensile Lattice Strain Accelerates Oxygen Surface Exchange and Diffusion in $\mathrm{La}_{1-\mathrm{x}} \mathrm{Sr}_{\mathrm{x}} \mathrm{CoO}_{3 \text {-delta }}$ Thin Films," ACS Nanom, 7 3276-86 (2013).

14. H. Tanaka, "An Intelligent Catalyst: the Self-Regenerative Palladium-Perovskite Catalyst for Automotive Emissions Control," Catal. Surv. Asia, 9 63-74 (2005).

15. D. Neagu, G. Tsekouras, D. N. Miller, H. Menard, and J. T. S. Irvine, "In situ Growth of Nanoparticles through Control of Non-Stoichiometry," Nature Chem., 5 916-923 (2013)

16. D. Neagu, T. S. Oh, D. N. Miller, H. Menard, S. M. Bukhari, S. R. Gamble, R. J. Gorte, J. M. Vohs, and J. T. S.
Irvine, "Nano-Socketed Nickel Particles with Enhanced Coking Resistance Grown in situ by Redox Exsolution," Nature Comm., 68120 (2015).

17. Y. Sun, J. Li, Y. Zeng, B. S. Amirkhiz, M. Wang, Y. Behnamian, and J. Luo, "A-site Deficient Perovskite: the Parent for in situ Exsolution of Highly Active, Regenerable Nanoparticles as SOFC anodes," J. Mater. Chem. A, 3 11048-056 (2015).

18. T. H. Shin, Y. Okamoto, S. Ida, and T. Ishihara, "SelfRecovery of Pd Nanoparticles That Were Dispersed over $\mathrm{La}(\mathrm{Sr}) \mathrm{Fe}(\mathrm{Mn}) \mathrm{O}_{3}$ for Intelligent Oxide Anodes of SolidOxisde Fuel Cells," Chem. -Eur. J. 18 [37] 11695-702 (2012)

19. G. Tsekouras, D. Neagu, and J. T. S. Irvine, "Step-Change in High Temperature Steam Electrolysis Performance of Perovskite Oxide Cathodes with Exsolution of B-site Dopants," Energy Environ. Sci., 6 256-66 (2013)

20. Y. Zhu, W. Zhou, R. Ran, Y. Chen, Z. Shao, and M. Liu, "Promotion of Oxygen Reduction by Exsolved Silver Nanoparticles on a Perovskite Scaffold for Low-Temperature Solid Oxide Fuel Cells," Nano Lett. 16 512-18 (2016). 